Marquette University

e-Publications@Marquette

Chemistry Faculty Research and Publications

Chemistry, Department of

$3-1-2006$

Applications of Acoustic Wave Devices for Sensing in Liquid Environments

Jeanne Hossenlopp

Marquette University, jeanne.hossenlopp@marquette.edu

Published version. Applied Spectroscopy Reviews, Vol. 41, No. 2 (March-April 2006): 151-164. DOI.

(C) 2006 Taylor \& Francis. Used with permission. 


\title{
Applications of Acoustic Wave Devices for Sensing in Liquid Environments
}

\author{
Jeanne M. Hossenlopp \\ Chemistry, Marquette University \\ Milwaukee, WI
}

Acoustic wave devices such as thickness shear mode (TSM) resonators and shear horizontal surface acoustic wave (SH-SAW) devices can be utilized for characterizing physical properties of liquids and for chemical sensor applications. Basic device configurations are reviewed and the relationships between experimental observables (frequency shifts and attenuation) and physical properties of liquids are presented. Examples of physical property (density and viscosity) determination and also of chemical sensing are presented for a variety of liquid phase applications. Applications of TSMs and polymer-coated guided SH-SAWs for chemical sensing and uncoated $\mathrm{SH}$ SAWs for "electronic tongue" applications are also discussed.

\section{Introduction}

Acoustic wave devices can be effectively utilized for a wide range of chemical and biochemical sensing applications. These devices consist of a sensor platform that is typically, although not always,

Applied Spectroscopy Reviews, Vol. 41, No. 2 (2006): pg. 151-164. DOI. This article is @ Taylor \& Francis and permission has been granted for this version to appear in e-Publications@Marquette. Taylor \& Francis does not grant permission for this article to be further copied/distributed or hosted elsewhere without the express permission from Taylor \& Francis. 
coated with a polymer or other material to impart biochemical or chemical sensitivity, and some degree of selectivity. The use of acoustic wave devices in gas sensing applications is well-established and a number of review articles are available on this topic (1-5). For chemical sensing applications, the devices are typically used in sensor arrays that include a number of devices with different polymer coatings $(6,7)$. A variety of signal processing approaches can be applied to sensor array data in order to analyze mixtures of analytes (8).

Use of acoustic wave devices for sensing in liquid environments, including characterization of physical properties of liquids is a newer area of research and a number of different device platforms can be used for this purpose such as thickness shear mode (TSM) resonators, also commonly referred to as the quartz crystal microbalances (QCM), or, more properly, quartz crystal resonators (QCR) (9), acoustic plate mode (APM) (10), and guided shear horizontal surface acoustic wave (SH-SAW) devices (11). The primary focus of this review will be on recent developments in use of TSM and guided SH-SAW devices for chemical sensing. Related characterization of liquid properties will also be briefly reviewed.

\section{Device Platforms}

\section{Thickness Shear Mode (TSM) Resonators}

TSM resonators are single-port (two-terminal) devices (12) that are typically made from thin disks of AT-cut quartz but can also be fabricated from other piezoelectric materials. Electrodes are printed on each side of the disk as shown schematically in Figure 1A. An oscillating electrical field is applied to the electrodes, resulting in acoustic wave propagation perpendicular to the substrate surface and particle displace parallel the surface. The particle displacement makes these devices sensitive to physical properties of liquids at the sensorliquid interface, useful for characterizing viscosity. Device thicknesses on the order of $10^{-4} \mathrm{~m}$ will result in fundamental resonant frequencies in the range of $5-15 \mathrm{MHz}(12)$. In the limit of mass loading effects only, the Sauerbrey equation can be used to relate frequency shifts, $\Delta f$, from the resonant frequency $f_{0}$, to added mass, $m_{f}(12)$,

Applied Spectroscopy Reviews, Vol. 41, No. 2 (2006): pg. 151-164. DOI. This article is (C) Taylor \& Francis and permission has been granted for this version to appear in e-Publications@Marquette. Taylor \& Francis does not grant permission for this article to be further copied/distributed or hosted elsewhere without the express permission from Taylor \& Francis. 
NOT THE PUBLISHED VERSION; this is the author's final, peer-reviewed manuscript. The published version may be accessed by following the link in the citation at the bottom of the page.

$$
\Delta f=-\frac{2 f_{0}^{2}}{\sqrt{\mu_{s} \rho_{s}}} \frac{m_{f}}{A}
$$

where $\mu_{s}$ is the shear modulus of the substrate, $\rho_{s}$ is the substrate density, and $A$ is the area of one surface of the substrate. For chemical sensing applications, one surface of the device is typically coated with a polymer coating in order to achieve partial selectivity.

\section{Guided Shear Horizontal Surface Acoustic Wave (SH- SAW) Devices}

Guided SH-SAW sensors are particularly attractive for liquid phase sensing applications due to the high sensitivities that can be obtained $(11,13)$. A simple schematic is shown in Figure 1B. Guided SH-SAWs are two-port devices where input and output interdigitated transducers (IDTs) are utilized to generate and detect the acoustic wave respectively. Acoustic interactions with the liquid load are minimized by using a metallized delay line. A dual delay line configuration, where second line is also included on the same substrate, is used to provide both a sensor and a reference line, which can be used to control for drifts due to changes in environmental conditions such as temperature fluctuations. Substrates can be fabricated from $36^{\circ} \mathrm{YX}-\mathrm{LiTaO}_{3}$ and with proper choice of IDT finger design, the devices can operate in the range of $\sim 103 \mathrm{MHz}(11,13)$.

The IDTs and the delay line are coated with a dielectric material, such as a polymer, which serves as a waveguiding layer to trap the acoustic wave near the surface, increasing sensitivity, while also protecting the IDTs from the contacting liquid medium. The reference line is typically coated with a wave-guiding layer of a chemically inert layer that does not significantly sorb analytes of interest, while the sensor line is coated with a polymer chosen for sensitivity and partial selectivity toward target analytes. The chemically sensitive polymer can also serve as the waveguide (13).

Applied Spectroscopy Reviews, Vol. 41, No. 2 (2006): pg. 151-164. DOI. This article is C Taylor \& Francis and permission has been granted for this version to appear in e-Publications@Marquette. Taylor \& Francis does not grant permission for this article to be further copied/distributed or hosted elsewhere without the express permission from Taylor \& Francis. 


\section{Liquid Sensor Examples}

\section{Characterizing Physical Properties of Liquid Samples}

The viscoelasticity and density of liquid samples can be characterized using TSM (14) or SH-SAW (15) resonators. In the case of a Newtonian fluid on a TSM resonator, the observed frequency shift, $\Delta f_{\mathrm{s}}$, can be related as shown in Eq. (2) (12) to the device frequency, $f_{s}$, mass density, and dynamic viscosity of the fluid in contact with the device, $\rho$ and $\eta$, respectively, and the shear stiffness and mass density of the quartz resonator, $\mu_{\mathrm{q}}$ and $\rho_{\mathrm{q}}$.

$$
\Delta f_{s} \cong-f_{s}^{3 / 2}\left(\frac{\rho \eta}{\pi \mu_{q} \rho_{q}}\right)^{1 / 2}
$$

The ability to characterize viscosity has recently been utilized to monitor microbial activity (16). An anaerobic bacterial strain, designated in reference 16 as JEL-1, was isolated from river sediments that had been contaminated with hydrocarbons. In the presence of amino acids or sugars, JEL-1 produced a gelatinous polymer. An ATcut $10 \mathrm{MHz}$ quartz TSM resonator was used to determine changes in solution viscoelasticity using Eq. (2) along with measured solution densities. In the first 10 days after inoculation of the bacterial solution with nutrients, the changes in solution viscosity measured with the TSM resonator were found to agree with rheometer measurements, with an observed increase of $0.1 \mathrm{cP}$ after 10 days. At longer times (up to 30 days) the viscosity changes measured with the TSM were found to level off between 0.1 and $0.2 \mathrm{cP}$, while the rheometer measurement indicated that the viscosity continued to increase by nearly $1.1 \mathrm{cP}$ over the 30-day time period. This suggests that the continued microbial polymer production led to formation of a non-Newtonian fluid where Eq. (2) was no longer valid. However, the TSM method provided a convenient means of monitoring the early stages of biopolymer formation.

Use of acoustic wave devices to monitor physical properties of automotive fluids has recently been reviewed (17). Permittivity and conductivity of a fluid can be obtained from SH-SAW measurements

Applied Spectroscopy Reviews, Vol. 41, No. 2 (2006): pg. 151-164. DOI. This article is @ Taylor \& Francis and permission has been granted for this version to appear in e-Publications@Marquette. Taylor \& Francis does not grant permission for this article to be further copied/distributed or hosted elsewhere without the express permission from Taylor \& Francis. 
using Eqs. (3) and (4). The relative changes in velocity $(\Delta V / V)$ and attenuation $(\Delta \alpha / k)$ can be related to $K^{2}$ s, the electromagnetic coupling coefficient for an unperturbed liquid on the free surface of the $\mathrm{SH}$ SAW; $\delta$, the conductivity of the solution; $\omega$, the angular frequency; $\varepsilon_{0}$, the permittivity of free space; $\varepsilon_{r}$, the relative permittivity of unperturbed liquid, i.e., pure water for aqueous systems; $\varepsilon^{\prime}{ }_{r}$, the relative permittivity of the solution; and $\varepsilon^{\top}$, the effective permittivity of the SAW crystal (18).

$$
\begin{gathered}
\frac{\Delta V}{V}=-\frac{K_{s}^{2}}{2} \frac{\left(\sigma^{\prime} / \omega\right)^{2}+\varepsilon_{0}\left(\varepsilon_{r}-\epsilon_{r}\right)\left(\varepsilon_{r} \varepsilon_{0}+\varepsilon_{p}^{T}\right)}{\left(\sigma^{\prime} / \omega\right)^{2}+\left(\varepsilon_{r} \varepsilon_{0}+\varepsilon_{p}^{T}\right)^{2}} \\
\frac{\Delta a}{k}=\frac{K_{s}^{2}}{2} \frac{\left(\sigma^{\prime} / \omega\right)\left(\varepsilon_{r} \varepsilon_{0}+\varepsilon_{P}^{T}\right)}{\left(\sigma^{\prime} / \omega\right)^{2}+\left(\varepsilon_{r} \varepsilon_{0}+\varepsilon_{p}^{T}\right)^{2}}
\end{gathered}
$$

Figure 2 shows the result of simultaneous determination of viscosity and permittivity of motor oil samples that have been subjected to $19,000 \mathrm{~km}$ of test driving (used oil) and to cold start tests, 15 starts at $-15^{\circ} \mathrm{C}$, which is expected to lead to dilution of the oil by fuel (18). The oil sample that was aged by driving exhibited an increase in viscosity and permittivity while the fuel diluted sample exhibited a decrease in viscosity and little change in permittivity. The resulting changes were consistent with expectations based on the physical properties of the expected contaminants, demonstrating the utility of dual property characterization in analyzing oil degradation pathways.

\section{Chemical Sensing in Liquid Environments}

In addition to physical property measurements, TSMs have been shown to be useful in selected liquid-phase chemical sensing applications. Molecular imprinting (MIP) strategies have been utilized to optimize TSM coatings. For example, a copolymer of trimethylolpropane trimethacrylate (TRIM) and methacrylic acid (MAA) was imprinted with $S$-propranolol, a chiral $\beta$-blocking drug (19). After moderate crosslinking of the templated film on the TSM surface, the $S$ propranolol template was washed out. The TSM with the imprinted coating was then tested for sensitivity in detection of $S$-propranolol and selectivity of $S$ - over $R$-propanolol; the $S$-enantiomer was 


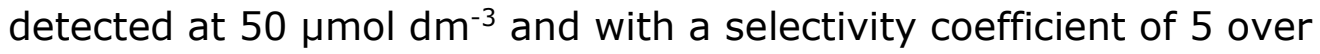
the $R$-enantiomer (19). Similarly, copolymers of ethylene glycol dimethacrylate (EDMA) and MAA were imprinted with L-menthol and tested for sensing monoterpene analogues (20). Reported sensitivity to L-menthol in ethanol was $200 \mathrm{ppb}$ with an enantiomeric sensitivity coefficient of 3.6 (20). General intermolecular interactions and size effects can be exploited in coating design to enhance selectivity. Use of different coating materials, such as self-assembled monolayers, calixarene derivatives, and polymer layers has shown to assist in selective detection of organic amines in liquid phases (21). Changes in coating properties due to supramolecular interactions with analytes have also been shown to contribute to TSM frequency shifts (22). TSM resonators are also frequently applied in conjunction with spectroscopy and microcroscopy analysis to explore binding of analytes. For example, binding of sucrose to Langmuir films of Dipalmitoylphosphatidylcholine has been evaluated via combined TSM and Fourier transform infrared reflection spectroscopy (23). Both TSM and SAW techniques have been combined with atomic force microscopy and surface plasmon resonance methods to investigate human immunoglobulin adsorption onto gold surfaces; protein surface coverage, conformation and layer organization, and water content were evaluated from the combined data (24).

While useful in many general sensing applications, the ultimate TSM sensitivity is limited in part due to the lower operating frequencies; in the limit of the Sauerbrey Eq. (1) frequency shifts are proportional to the square of the fundamental operating frequency. There have also been reports of immersion angle effects (25) when one surface of a TSM resonator is exposed to sucrose solutions (25b25e) and for TSMs with tethered DNA strands (25a), an effect that is attributed to gravitational effects, which furthermore may be concentration dependent (25b).

In contrast, guided SH-SAW devices are attractive platforms for developing chemical sensors (11). It is important to note that changes in polymer viscoelastic properties as well as mass loading effects contribute to the observed sensor response. In recent work in our laboratories, the effects of added mass, swelling of the polymer coating, and plasticization have been characterized for $\mathrm{LiTaO}_{3} \mathrm{SH}-\mathrm{SAW}$

Applied Spectroscopy Reviews, Vol. 41, No. 2 (2006): pg. 151-164. DOI. This article is (C) Taylor \& Francis and permission has been granted for this version to appear in e-Publications@Marquette. Taylor \& Francis does not grant permission for this article to be further copied/distributed or hosted elsewhere without the express permission from Taylor \& Francis. 
devices where the signal line had been coated with poly(isobutylene) (PIB), poly(epichlorohydrin) (PECH), or poly(ethyl acrylate) (PEA) (13). The responses of the coated devices to $1-60 \mathrm{ppm}$ aqueous solutions of toluene, ethyl benzene, and xylenes were compared to theoretical predictions. Two different configurations were tested and theoretically analyzed: a three-layer system that consisted of the device coated with a single polymer immersed in a semi-infinite Newtonian fluid (water) and a four-layer system consisting of the device, a waveguiding layer of poly(methyl methacrylate) (PMMA), and a chemically sensistive layer of PIB, PECH, or PEA. In the three-layer configuration the polymer coating serves as both waveguide and as the chemically sensitive material. The three-layer configuration was found to be more sensitive under the experimental conditions tested.

Figures 3 and 4 show results of the combined experimental and theoretical analyses for a $0.64-\mathrm{mm}$ PIB-coated guided SH-SAW exposed to toluene, xylenes, and ethyl benzene solutions. The frequency shifts predicted in the limit of mass loading only, shown in Figure 3a, are lower in magnitude than the experimentally measured shifts shown in Figure $3 \mathrm{~b}$. Note that changes in polymer height and density based on expected partitioning were accounted for in the theoretical analysis using an adaptation of the free volume model used for analysis of gas sensing (26). In order to correct for changes in polymer viscoelasticity due to adsorption of analytes, an empirical approach for adjusting the polymer shear loss and storage moduli based on observed acoustic losses was developed (13). Figure 4 shows the resulting predictions based on assuming an order of magnitude change in the shear modulus when a PIB-coated device was exposed to $60 \mathrm{ppm}$ ethyl benzene; shear moduli for other concentrations and/or analytes were estimated based on ratios of observed acoustic losses.

The importance of considering changes in viscoelasticity in modeling guided $\mathrm{SH}-\mathrm{SAW}$ sensor responses in liquid phase sensing is clear from the previous example. In the case of very rubbery polymer coatings such as poly (dimethyl siloxane), PDMS, this can result in anomalous frequency shifts (27), similar to behavior observed in gassensing applications (28). Figure 5 shows that upon exposure to aqueous ethyl benzene solutions, the frequency of a PDMS-coated 
guided SH-SAW increases, rather than decreases as normally expected. However, in the case of lightly crosslinked polymers, where the bulk modulus is large compared with the shear modulus, the relative frequency shift $\left(\Delta f / f_{0}\right)$ can be characterized in terms of the relative contributions of mass loading and viscoelastic changes by $(28 a, 29)$ :

$$
\frac{\Delta f}{f_{0}}=-c_{1} \omega \times \Delta(h p)-c_{2} \omega h \times \Delta\left[\frac{\mu(\omega \tau)^{2}}{1+(\omega \tau)^{2}}\right]
$$

where $c_{1}$ and $c_{2}$ represent substrate-dependent parameters, $\omega$ is the SAW angular frequency, $h$ is the film thickness, $\rho$ is the film mass density, $\mu$ is the polymer dynamic shear modulus, and $\mathrm{T}$ is the shear relaxation time of the polymer. The first term in Eq. (5) represents the mass-loading contribution that was shown in Eq. (1). The second term represents the viscoelastic contribution which can have either a net positive or a negative value depending on the value of $\omega T \approx 1$. The overall sign of the observed frequency shift will be negative where $\omega$ T $>>1$ and positive where $\omega \mathrm{T}<<1$ (30). In the region where $\omega \mathrm{T} \approx 1$, significant changes in the polymer relaxation time due to interaction of the coating with the analyte (as well as due to temperature changes) can lead to differences in the sign of the observed frequency shifts. The relationship between device angular frequency and the polymer shear relaxation time thus controls the sign of the observed frequency shift. The relaxation time can further be related to the shear modulus, $\mu$, and shear viscosity, $\eta$, of the polymer: $T=\eta / \mu(29)$.

Proper consideration of viscoelastic effects is clearly critical for quantifying guided $\mathrm{SH}-\mathrm{SAW}$ responses in liquid sensing, as is true in gas-sensing applications. However, the magnitude of the sensor response is generally linear with respect to concentration of the analyte, suggesting that both mass loading and viscoelastic effect contribute to the observed sensor response in proportion to the amount of analyte partitioned into the coating. Partition coefficients or equilibrium constants for partitioning of an analyte from water into a polymer coating can be estimated using literature parameters for linear free energy of solvation relationships (LFESR) (31). Alternatively, spectroscopic methods can be used. In our laboratory, attenuated total reflectance Fourier transform infrared spectroscopy

Applied Spectroscopy Reviews, Vol. 41, No. 2 (2006): pg. 151-164. DOI. This article is C Taylor \& Francis and permission has been granted for this version to appear in e-Publications@Marquette. Taylor \& Francis does not grant permission for this article to be further copied/distributed or hosted elsewhere without the express permission from Taylor \& Francis. 
(ATRFTIR) has been used as a rapid screening tool to estimate trends in partition coefficients. The integrated absorption of a specific analyte vibrational band when the analyte is absorbed into a polymer coating placed on an ATR prism can be compared with that of the analyte solution on a bare prism as shown in Eq. (6). The ratio of infrared intensities, $R_{I R}$, is compared with calculated partition coefficients and magnitude of the observed frequency shifts in Figure 6. After normalization with respect to toluene detection, the overall trends in each parameter show reasonable agreement, within the limits of experimental uncertainty. Note, however, that when comparing unnormalized data across the different polymers, the PDMS frequency shifts are smaller than would be predicted from partition coefficients or infrared measurements due to the offsetting mass loading and viscoelastic contributions in Eq. (5).

$$
R_{I R}=\frac{\left(\int_{v_{\text {lower }}}^{v_{\text {lopper }}} A(v) d v\right)_{\text {anulyte in polygner }}}{\left(\int_{v_{\text {lower }}}^{v_{\text {irpper }}} A(v) d v\right)_{\text {analyte in water }}}
$$

Differences in the extent of analyte partitioning and/or viscoelastic effects upon sorption of analytes can be exploited to construct sensor arrays capable of discriminating among a series of analytes via multivariate analysis. The ability to simultaneously determine changes in phase velocity and attenuation, Eqs. (3) and (4), can also be utilized to build sensor arrays that do not require polymer coatings. One approach has been to utilize a set of three SH-SAW devices with different center frequencies $(30,50$, and $100 \mathrm{MHz}$ ) to discriminate among a set of 11 different fruit juices via principal component analysis of the velocity shift and attenuation change (32). SH-SAW-based electronic tongues for distinguishing between sweet, bitter, salty, and sour liquids (33) (Figure 7) and between different liquid samples (milk, orange juice, and water) (30). These sensors were designed using $\mathrm{LiTaO}_{3}$ and $\mathrm{LiNbO}_{3} \mathrm{SH}-\mathrm{SAW}$ in a dual-delay line configurations with one line metallized (i.e., electrically shorted) and the second line left open. Velocity and attenuation changes were analyzed via principal component analysis. In the case of discriminating among different taste categories, a single $\mathrm{LiTaO}_{3}$ dual delay line SH-SAW was sufficient to distinguish between aqueous samples of $0.1 \mathrm{M} \mathrm{HCl}, \mathrm{NaCl}$, and sucrose, and $1.3 \times 10^{-4}$ quinine (33).

Applied Spectroscopy Reviews, Vol. 41, No. 2 (2006): pg. 151-164. DOI. This article is (C) Taylor \& Francis and permission has been granted for this version to appear in e-Publications@Marquette. Taylor \& Francis does not grant permission for this article to be further copied/distributed or hosted elsewhere without the express permission from Taylor \& Francis. 
NOT THE PUBLISHED VERSION; this is the author's final, peer-reviewed manuscript. The published version may be accessed by following the link in the citation at the bottom of the page.

\section{Conclusion}

Acoustic wave devices such as TSM and SH-SAWs can be utilized for characterization of liquid physical properties and for chemical sensing in liquid environments. SH-SAWs provide better sensitivity for chemical sensing. Selectivity for specific analytes can be enhanced for either device by selection of coatings. Use of polymer coated guided SH-SAW devices for chemical sensor applications is shown to require consideration of changes in coating viscoelastic properties along with mass-loading into the coating. Use of uncoated $\mathrm{SH}-\mathrm{SAWs}$ is also being explored for the development of "electronic tongues."

\section{References}

1. James, D., Scott, S.M., Ali, Z., and O'Hare, W.T. (2005) Chemical sensors for electronic nose systems. Microchim. Acta, 149: 1-17.

2. Cheeke, J.D.N. and Wang, Z. (1999) Acoustic wave gas sensors. Sensor. Actuator. B Chem., B59: 146-153.

3. Khlebarov, Z., Stoyanova, A., and Topalova, D. (1992) Surface acoustic wave gas sensors. Sensor. Actuator. B Chem., B8: 33-40.

4. Fox, C.G. and Alder, J.F. (1989) Surface acoustic wave sensors for atmospheric gas monitoring. A review. Analyst, 114: 997-1004.

5. Ali, Z. (1999) Acoustic wave mass sensors. Journal of Thermal Analysis and Calorimetry, 55: 397-412.

6. Grate, J.W. (2000) Acoustic wave microsensor arrays for vapor sensing. Chem. Rev., 100: 2627-2647.

7. Albert, K.J., Lewis, N.S., Schauer, C.L., Sotzing, G.A., Stitzel, S.E., Vaid, T.P., and Walt, D.R. (2000) Cross-reactive chemical sensor arrays. Chem. Rev., 100: 2595-2626.

8. Jurs, P.C., Bakken, G.A., and McClelland, H.E. (2000) Computational methods for the analysis of chemical sensor array data from volatile analytes. Chem. Rev., 100: 2649-2678.

9. Patel, R., Zhou, R., Zinszer, K., Josse, F., and Cernosek, R. (2000) Realtime detection of organic compounds in liquid environments using polymer-coated thickness shear mode quartz resonators. Anal. Chem., 72: 4888-4898.

Applied Spectroscopy Reviews, Vol. 41, No. 2 (2006): pg. 151-164. DOI. This article is (C) Taylor \& Francis and permission has been granted for this version to appear in e-Publications@Marquette. Taylor \& Francis does not grant permission for this article to be further copied/distributed or hosted elsewhere without the express permission from Taylor \& Francis. 
NOT THE PUBLISHED VERSION; this is the author's final, peer-reviewed manuscript. The published version may be accessed by following the link in the citation at the bottom of the page.

10. Bender, F., Dahint, R., Josse, F., Ricco, A.J., and Martin, S.J. (1999) Characteristics of acoustic plate modes on rotated $\mathrm{Y}$-cuts of quartz utilized for biosensing applications. Anal. Chem., 71: 5064-5068.

11. Josse, F., Bender, F., and Cernosek, R.W. (2001) Guided shear horizontal surface acoustic wave sensors for chemical and biochemical detection in liquids. Anal. Chem., 73: 5937-5944.

12. Ballantine, D.S., White, R.M., Martin, S.J., Ricco, A.J., Zellers, E.T., Frye, G.C., and Wohltjen, H. (1997) Acoustic Wave Sensors: Theory, Design, and Physico-Chemical Applications; Academic Press: San Diego, CA.

13. Li, Z., Jones, Y., Hossenlopp, J., Cernosek, R., and Josse, F. (2005) Analysis of liquid-phase chemical detection using guided shear horizontal-surface acoustic wave sensors. Anal. Chem., 77: 45954603.

14. (a) Lucklum, R., Schranz, S., Behling, C., Eichelbaum, F., and Hauptmann, P. (1997) Analysis of compressional-wave influence on thickness-shear-mode resonators in liquids. Sensor. Actuator. A Phys., A60: 40-48; (b) Martin, S.J., Frye, G.C., and Wessendorf, K.O. (1994) Sensing liquid properties with thickness-shear mode resonators. Sensor. Actuator. A Phys., 44: 209-218; (c) Moritake, H., Inoue, M., and Toda, K. (1997) Liquid viscosity measurement using plate mode shear horizontal waves on a piezoelectric ceramic thin plate. Jpn. J. Appl. Phys. 1, 36: 6088-6091; (d) Nwankwo, E. and Durning, C.J. (1999) Fluid property investigation by impedance characterization of quartz crystal resonators. Part II: parasitic effects, viscoelastic fluids. Sensor. Actuator. A Phys., A72: 195-202; (e) Schoen, P., Michalek, R., and Walder, L. (1999) Liquid density response of a quartz crystal microbalance modified with mesoporous titanium dioxide. Anal. Chem.,71: 3305-3310; (f) Yang, M. and Thompson, M. (1993) Multiple chemical information from the thickness shear mode acoustic wave sensor in the liquid phase. Anal. Chem., 65: 3591-3597; (g) Zhang, C., Schranz, S., and Hauptmann, P. (2000) Surface microstructures of TSM resonators and liquid properties measurement. Sensor. Actuator. B Chem., B65: 296-298.

15. (a) Nomura, T., Saitoh, A., and Horikoshi, Y. (2001) Measurement of acoustic properties of liquid using liquid flow SH-SAW sensor system. Sensor. Actuator. B Chem., B76: 69-73; (b) Kondoh, J., Hayashi, S., and Shiokawa, S. (2001) Simultaneous detection of density and viscosity using surface acoustic wave liquid phase sensors. Jpn. J. Appl. Phys. 1, 40: 3713-3717.

Applied Spectroscopy Reviews, Vol. 41, No. 2 (2006): pg. 151-164. DOI. This article is (C) Taylor \& Francis and permission has been granted for this version to appear in e-Publications@Marquette. Taylor \& Francis does not grant permission for this article to be further copied/distributed or hosted elsewhere without the express permission from Taylor \& Francis. 
16. Gee, W.A., Ritalahti, K.M., Hunt, W.D., and Loffler, F.E. (2003) QCM viscometer for bioremediation and microbial activity monitoring. IEEE Sensor. J., 3:304-309.

17. Jakoby, B., Eisenschmid, H., and Herrman, F. (2002) The potential of microacoustic SAW-and BAW-based sensors for automotive applications-A review. IEEE Sensor. J., 2: 443-452.

18. Kondoh, J., Saito, K., Shiokawa, S., and Suzuki, H. (1996) Simultaneous measurements of liquid properties using multichannel shear horizontal surface acoustic wave microsensor. Jpn. J. Appl. Phys. 1, 35: 30953096.

19. Haupt, K., Noworyta, K., and Kutner, W. (1999) Imprinted polymer-based enantioselective acoustic sensor using a quartz crystal microbalance. Anal. Comm., 36: 391-393.

20. Percival, C.J., Stanley, S., Galle, T.M., Braithwaite, A., Newton, M.I., McHale, G., and Hayes, W. (2001) Molecular-imprinted, polymercoated quartz crystal micro-balances for the detection of terpenes. Anal. Chem., 73: 4225-4228.

21. Zhou, X.C., Ng, S.C., Chan, H.S.O., and Li, S.F.Y. (1997) Detection of organic amines in liquid with chemically coated quartz crystal microbalance. Sensor. Actuator. B Chem., B42: 137-144.

22. Hartmann, J., Auge, J., Lucklum, R., Roesler, S., Hauptmann, P., Adler, B., and Dalcanale, E. (1996) Supramolecular interactions on mass sensitive sensors in gas phases and liquids. Sensor. Actuator. $B$ Chem., B34: 305-311.

23. Hasegawa, T., Nishijo, J., and Umemura, J. (1998) Binding mechanism of sucrose to dipalmitoylphosphatidylcholine Langmuir films by Fourier transform infrared reflection-absorption spectroscopy and quartzcrystal microbalance technique. J. Phys. Chem. B, 102: 8498-8504.

24. Zhou, C., Friedt, J., Angelova, A., Choi, K., Laureyn, W., Frederix, F., Francis, L.A., Campitelli, A., Engelborghs, Y., and Borghs, G. (2004) Human immunoglobulin adsorption investigated by means of quartz microbalance dissipation, atomic force microscopy, surface acoustic wave, and surface plasmon resonance techniques. Langmuir, 20: 5870-5878.

25. (a) Fawcett, N.C., Craven, R.D., Zhang, P., and Evans, J.A. (2004) Evidence for gravity's influence on molecules at a solid-solution interface. Langmuir, 20: 6651-6657; (b) Maruyama, Y., Yoshimoto, M., Kurosawa, S., and Naito, M. (2004) Behaviors of the quartz crystal

Applied Spectroscopy Reviews, Vol. 41, No. 2 (2006): pg. 151-164. DOI. This article is (c) Taylor \& Francis and permission has been granted for this version to appear in e-Publications@Marquette. Taylor \& Francis does not grant permission for this article to be further copied/distributed or hosted elsewhere without the express permission from Taylor \& Francis. 
microbalance in a Newtonian liquid. Chem. Sens., 20: 838-839; (c) Yoshimoto, M., Abe, K., Nishikanbara, M., and Kurosawa, S. (2004) Immersion-angle dependence of a single-face sealed quartz crystal microbalance using an oscillation circuit. Instrum. Sci. Tech., 32: 353360; (d) Yoshimoto, M. and Kurosawa, S. (2002) Effect of immersion angle of a one-face sealed quartz crystal microbalance in liquid. Anal. Chem., 74: 4306-4309; (e) Yoshimoto, M., Tokimura, S., Shigenobu, K., Kurosawa, S., and Naito, M. (2004) Properties of the overtone mode of the quartz crystal microbalance in a low-viscosity liquid. Anal. Chim. Acta, 510: 15-19.

26. Martin, S.J., Frye, G.C., and Senturia, S.D. (1994) Dynamics and response of polymer-coated surface acoustic wave devices: effect of viscoelastic properties and film resonance. Anal. Chem., 66: 22012219.

27. Jones, Y.K., Li, Z., Josse, F., and Hossenlopp, J.M. (2005) ATR-FTIR spectroscopic analysis of sorption of aqueous analytes into polymer coatings used with guided SH-SAW sensors. IEEE Sensor. J., 5: 11751184.

28. (a) Ahuja, A., James, D.L., and Narayan, R. (1999) Dynamic behavior of ultra-thin polymer films deposited on surface acoustic wave devices. Sensor. Actuator., 72: 234-241; (b) Bodenhöfer, K., Hierlemann, A., Noetzel, G., Wiemar, U., and Göpel, W. (1996) Performance of masssensitive devices for gas sensing: thickness shear mode and surface acoustic wave transducers. Anal. Chem., 68: 2210-2218; (c) Reibel, J., Stier, S., Voigt, A., and Rapp, M. (1998) Influence of phase position on the performance of chemical sensors based on SAW device oscillators. Anal. Chem., 70: 5190-5197.

29. Martin, S.J. and Frye, G.C. (1990) Surface acoustic wave response to changes in viscoelastic film properties. Appl. Phys. Lett., 57: 18671869.

30. Cole, M., Sehra, G., Gardner, J.W., and Varadan, V.K. (2004) Development of smart tongue devices for measurement of liquid properties. IEEE Sensor. J.,4: 543-550.

31. Grate, J.W., Snow, A., Ballantine, D.S., Jr., Wohltjen, H., Abraham, M.H., McGill, R.A., and Sasson, P. (1988) Determination of partition coefficients from surface acoustic wave vapor sensor responses and correlation with gas-liquid partition coefficients. Anal. Chem., 60: 869875.

Applied Spectroscopy Reviews, Vol. 41, No. 2 (2006): pg. 151-164. DOI. This article is (C) Taylor \& Francis and permission has been granted for this version to appear in e-Publications@Marquette. Taylor \& Francis does not grant permission for this article to be further copied/distributed or hosted elsewhere without the express permission from Taylor \& Francis. 
32. Kondoh, J. and Shiokawa, S. (1994) New application of shear horizontal surface acoustic wave sensors to identifying fruit juices. Jpn. J. Appl. Phys., 33: 3095-3099.

33. Sehra, G., Cole, M., and Gardner, J.W. (2004) Miniature taste sensing system based on dual SH-SAW sensor device: an electronic tongue. Sensor. Actuator. B Chem., B103: 233-239.

\section{Appendix}

\section{Figure 1}

A

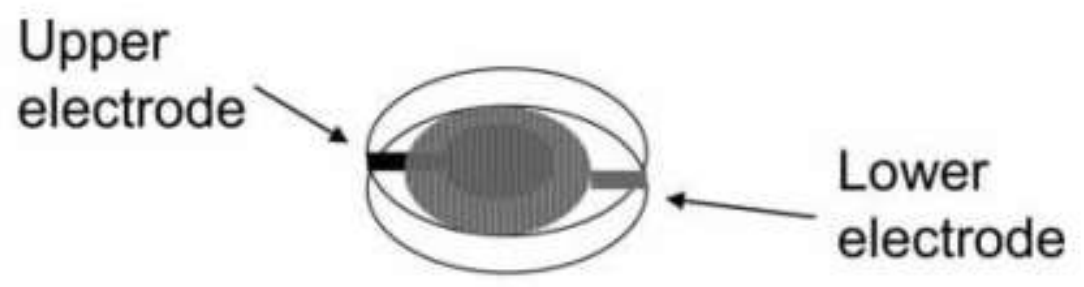

B

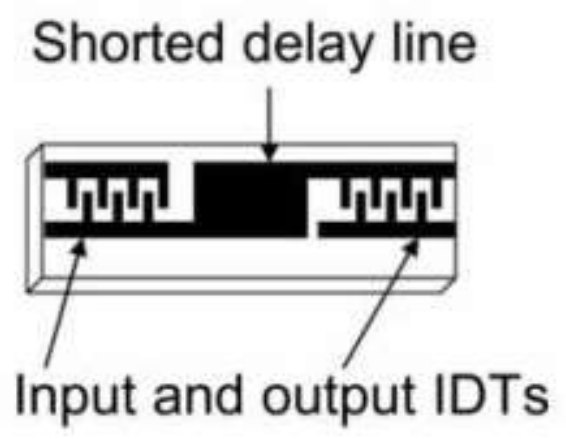

Schematic representation of: A) TSM resonator and B) SH-SAW device platforms. Only a single delay line is shown on the SH-SAW substrate.

\section{Figure 2}

Image unavailable due to third-party copyright restrictions. Please see definitive published version to view image: DOI: $10.1080 / 05704920500510745$

Simultaneous measurement of viscosity and permittivity of motor oils measured @ $25^{\circ} \mathrm{C}$. 
NOT THE PUBLISHED VERSION; this is the author's final, peer-reviewed manuscript. The published version may be accessed by following the link in the citation at the bottom of the page.

\section{Figure 3}

Image unavailable due to third-party copyright restrictions. Please see definitive published version to view image: DOI:

$10.1080 / 05704920500510745$

Sensitivity comparison of $0.64 \mu \mathrm{m}$ PIB coated guided SH-SAW sensor platform in the detection of toluene, xylense, and ethylbenzene in DI water. (a) Calculated responses based on the predicted added mass load derived from water/polymer partition coefficients. (b) Experimental results.

\section{Figure 4}

Image unavailable due to third-party copyright restrictions. Please see definitive published version to view image: DOI:

$10.1080 / 05704920500510745$

Selectivity comparison of $0.64 \mu \mathrm{m}$ PIB coated guided SH-SAW sensor platform in the detection of toluene, xylenes, and ethylbenzene in DI water: The solid lines are the simulation result predicted added mass loading and incremental viscoelastic changes based on experimental loss data. The dashed lines show the experimental results.

\section{Figure 5}

Image unavailable due to third-party copyright restrictions. Please see definitive published version to view image: DOI:

10.1080/05704920500510745

Baseline-corrected frequency shifts versus analyte concentrations for a guided SH-SAW coated with PDMS exposed to flowing solutions: of 25$125 \mathrm{ppm}(0.2-1 \mathrm{mM})$ ethylbenzene (circles), and to 200-800 ppm (1.6$6.3 \mathrm{mM}$ ) nitrobenzene (triangles).

\section{Figure 6}

Image unavailable due to third-party copyright restrictions. Please see definitive published version to view image: DOI:

10.1080/05704920500510745

Response trends for ATR-FTIR $R_{I R}$, absolute values of guided SH-SAW frequency shifts, and predicted partition coefficients for PDMS, PECH, and PIB exposed to four model analytes. All values for a given coating are normalized with respect to the corresponding value for toluene.

Applied Spectroscopy Reviews, Vol. 41, No. 2 (2006): pg. 151-164. DOI. This article is (c) Taylor \& Francis and permission has been granted for this version to appear in e-Publications@Marquette. Taylor \& Francis does not grant permission for this article to be further copied/distributed or hosted elsewhere without the express permission from Taylor \& Francis. 
NOT THE PUBLISHED VERSION; this is the author's final, peer-reviewed manuscript. The published version may be accessed by following the link in the citation at the bottom of the page.

\section{Figure 7}

Image unavailable due to third-party copyright restrictions. Please see definitive published version to view image: DOI:

10.1080/05704920500510745

Principal component analysis results for SH-SAW electronic tongue. 